\title{
Integration of Big Data with International Graduate Ideological and Political Education
}

\author{
Mengzhen Li, Yu Deng, Xiaodong Wang*, Huizhen Zhao \\ School of Foreign Languages, Central South University, Changsha 410083, Hunan Province, China \\ *Corresponding author: Xiaodong Wang, cstdxy2008@126.com
}

Copyright: ( $) 2022$ Author(s). This is an open-access article distributed under the terms of the Creative Commons Attribution License (CC BY 4.0), permitting distribution and reproduction in any medium, provided the original work is cited.

\begin{abstract}
Nowadays, colleges and universities have a large amount of information about political thought and education in addition to complex student data. Like big data, it has the characteristics of large capacity, high speed, and diversity. The ideological and political education in colleges and universities urgently needs scientific decision-making and the ability to predict possible problems ahead of time. It also perfectly matches the technical advantages of big data technology that can efficiently process data, analyze and extract information, as well as propose solutions. The traditional higher education model can no longer meet the needs of current international higher education. Under the new background, universities must explore a new model of postgraduate international education, which is practical, multi-channel, and comprehensive, on a deeper level. According to data on graduate students' interest, psychology, and behavior, higher education teachers can purposefully innovate the methods and approaches to higher education. The integration of international graduate education with big data has been examined in this research, and a series of cultural exchanges has been carried out for foreign students at Central South University. This kind of introduction seems to have effectively boosted the attractiveness of ideological and political education, improved the research level of international graduate students, and deepened the role of campus cultural activities in educating people on a deeper level.
\end{abstract}

Keywords: Big data; Ideological and political education; Campus cultural activities

Online publication: January 12, 2022

\section{Introduction}

With the rapid development of network technology and data processing technology in the 21 st century, big data, a cutting-edge technology, has brought about new challenges and opportunities. It is characterized by the large scale, fast speed, and diversification of big data. It has been organically integrated with the general trend of education. It also has associations with multiple disciplines. This research examines how the integration of big data with education can be more effective. The high-capacity function of big data provides a large amount of statistical data for university educators to solve basic scientific problems. The high-speed transmission of big data ensures the efficiency of higher education decision-making to a certain extent and promotes the efficiency of science and education on a deeper level. The diversity of a large amount of data helps educators collect data related to the internet and students as well as use the HIVE database to build a large amount of data to provide content that matches the interest and psychological ideas of the students ${ }^{[1]}$.

At present, some universities do not pay enough attention to postgraduate-related management work; rather, they focus on cultivating academic skills after international degrees. Strengthening education and research as well as expanding deeper thinking must be more effective to improve the education of 
international graduate schools. The content of textbooks is not new, and its relevance, readability, and effectiveness need to be improved. All these have become urgent problems that need to be solved in current graduate schools. In the selection of teachers, there are also shortcomings in training. The team structure must be optimized; in addition, the overall quality, institutional mechanism, and evaluation support system need to be improved.

Ideological and political education can improve the overall quality of the people and promote the allround development of people. Only when the outlook on life and values improve, people can then be good. The great revival of the People's Republic of China can only hope for the Chinese culture to spread. Under the guidance of an important figure of China, various schools in Central South University, such as the School of Civil Engineering, the School of International Education, and the School of Foreign Languages, should work together to plan a cultural exchange festival for international students, so that educational ideas can penetrate all aspects of academic cultural activities. This activity has developed into a branded academic cultural activity with college characteristics and influence. Through accurate analysis of large amounts of data (such as international graduate survey questionnaires), teachers can develop more targeted models and methods, better carry out activities, and attract more international graduate students to actively participate in the ideological and political education implemented by the school.

\section{Integration of big data with postgraduate ideological and political education}

\subsection{Ideological and political education broadens the way for academic activities}

The integration of ideological and political education and academic activities can improve the academic ethics, scientific spirit, and sense of responsibility of graduate students, realize the great rejuvenation of the Chinese dream of the Chinese nation, as well as make it easier for graduate students to understand their significance and true meaning. Ideological and political educators in colleges and universities must make full use of this opportunity to improve the quality of ideological and political education. International student exchange cultural activities through the film "My Motherland and Me" had more than 90 international students, from Pakistan, Thailand, Nigeria, Russia, Afghanistan, and other 14 countries, participating in the event. Ideological and political educators should closely focus on current themes and the needs of international graduates through processing and data analysis, in order to obtain the most relevant information points for graduate students. For example, many international graduate students focus on China's cutting-edge technology; in addition, social economy and Chinese culture are also hotspots among international graduate students. Other than that, during the International Graduate Festival, schools should invite outstanding graduate students to the campus to bring China's cutting-edge technology to international graduate students for explanation. At the same time, it is necessary to organize an entry point in China to carry out exchanges and other activities, so as to create a platform for international graduate students to share freely.

\subsection{Ideological and political education aims at the innovation of scientific work}

Teachers should add the "salt" of good public education to innovative activities, so that the spirit of innovation and teamwork can penetrate into the minds of students, making them more innovative and energetic. The successful holding of the China High-Speed Railway Health Management Technology Forum demonstrates the spirit of teamwork. It focuses on the development of green and sustainable highspeed railway industries as well as the status and development trend of mobile internet to improve the innovation and practice of graduate students. 


\subsection{Political thoughts and education add color to cultural activities}

Integrating political and ideological education into cultural activities can revitalize a variety of cultural activities and implement the basic values of socialism. After the annual academic cultural festival, the ideological and political education team should collect feedback from graduate students. This information provides a large amount of data support for subsequent activities. At the same time, according to several students, it is understood that through online questionnaires and offline surveys, the needs of the relevant parties have established a similar information database. The organization and planning of academic cultural festivals as well as activities do not only exercise the personal abilities of graduates, but also cultivate the spirit of cooperation in the team. The design of campus sports includes cultural and sports activities, such as tug-of-war, three-legged race, etc., to improve the cohesion of students and their enthusiasm for participation in campus life. At the International Student Cultural Exchange Festival, 53 international student representatives from 14 countries and several Chinese students formed 19 participating teams. After nearly two months of careful preparation, they jointly presented a splendid cultural feast for the audience. At the event, the international students wore national costumes and shared the customs of their country as well as their feelings while studying in China in Mandarin. The judges scored each team in terms of theme expression, interaction, and on-site effects. Six teams were selected in view of their excellent performance. Good teamwork makes students more innovative and vigorous. It is a traditional Chinese and foreign culture for both Chinese and foreign students. A bridge of friendship should be built while focusing on promoting exchanges and cooperation among countries.

\section{Effectiveness of the integration of big data with postgraduate ideological and political education}

Big data has a positive role in promoting ideological and political education for graduate students. Big data has innovated the methods of ideological and political education for graduate students. In a real sense, ideological and political education can penetrate into all aspects of life through academic culture, so as to achieve the purpose of enhancing vitality as well as nourishing the body and mind. The effectiveness of the integration of big data with postgraduate ideological and political education can be reflected in three aspects. The use of big data has enhanced the attractiveness of ideological and political education. Cultural exchange activities for international students are derived from the students themselves and are student oriented. Based on the questionnaire survey before the cultural festival, the college combines years of data analyses and accurate services to summarize the aspirations of students and ensure that "every aspect of the activity is a student's favorite activity." By participating in the academic cultural festival, sharing the world's feelings, and realizing the integration of the Chinese dream, international graduate students can feel the scientific spirit and sense of responsibility concealed in the academic world, and at the same time, they can improve their innovative consciousness and innovative skills on a deeper level; namely, team spirit.

The application of big data can improve the research level of graduate students on a deeper level. Cultural exchange activities are mainly aimed at graduate students, and various forms of academic exchanges, laboratory visits, and other activities are carried out ${ }^{[2]}$. Its purpose is to create a strong academic environment, stimulate international graduate research and research enthusiasm, as well as significantly improve the overall quality and innovation capabilities. Through years of data analyses, the cultural exchange activities for international students have improved the "combination of educational, fun, and practical" methods to promote better and faster improvement of the international level of postgraduate research.

The application of big data can strengthen the educational function of campus cultural activities on a deeper level. Students majoring in technical sciences are usually busy with their academic and practical activities, and they tend to have little enthusiasm for campus cultural activities. Science and engineering students need to improve their own humanities. The development and improvement of humanistic quality 
among technical science graduates not only depend on the opportunity to receive primary education in classroom or other systems, but also on more subtle construction and influence of cultural activities that supplement primary education on campus ${ }^{[3]}$. The cultural exchanges of the Ministry of Architecture and Technology Visiting the National Laboratory of High-Speed Railway Engineering, the camera locomotive, and other colorful international activities have effectively fostered graduate educators to develop noble emotions, fight for one's life and values, as well as sublimate the resistance to war ideas, enabling international graduate students to better integrate with the Chinese culture and feel its richness.

\section{Thoughts and enlightenment of the integration of big data with postgraduate ideological and political education}

With the rapid development of the times, educational methods and teaching approaches have also undergone changes. The times have posed new challenges to several educational issues. Today, with the rapid development of science and technology, including data applications, the integration of big data with postgraduate ideological and political education have given people new thoughts and enlightenment in the new era.

\subsection{Making good use of big data to strengthen postgraduate scientific education and research}

In this great era, university management is given new opportunities but is facing new challenges; in addition, educational media is also transforming. How to make better use of big data and ensure that the academic cultural festival plays an irreplaceable role in higher education and even international postgraduate education is an important subject worth pondering about ${ }^{[4]}$. Teachers in the field of university management should use the knowledge of big data to analyze the opportunities and challenges that big data brings to the field of university management. New ideas and methods should also be proposed to keep up with the pace of the times. At the same time, universities should increase support and investment in postgraduate research on governance education; for example, by creating a topic for postgraduate education in governance. In addition, different colleges should explore new teaching methods, while taking into account the specific characteristics of the citizens and completing post-government courses based on the actual situation of the college.

\subsection{Closely focusing on big data platform to improve the subjective initiative of graduate students}

Educators must fully understand the characteristics and basic values of the great era. At the same time, it is important to effectively introduce big data to the university management committee, continue to build a network platform, and improve education in the field of university management. The request indicates that various teaching contents on ideological and political education have been transferred to the online platform. This kind of miniature carrier of human needs-oriented educational activities is very important. At the same time, it is also necessary to understand the detailed information, objects, softness, and stimulus, assume the results as the orientation, and allow educational activities to grow closer to one's spiritual needs after graduation ${ }^{[5]}$. This approach helps to attract graduate students to actively participate in ideological and political education and to a certain extent, improve the effectiveness of this education by emphasizing its unique charm in the new era.

\subsection{Using big data to integrate ideological and political education into the whole process of postgraduate training}

In fact, it has been proven that ideological and political educators in colleges and universities need the help of big data, which is indeed useful for analyzing the needs of graduate students in their learning, life, and 
characteristics. In the era of continuous education ${ }^{[6]}$, with full consideration of the multi-disciplinary characteristics and difficulties of international graduate students, ideological and political educators should establish different levels of ideological and political education priorities and integrate ideological and political education throughout the entire process of learning, evaluation, thesis defense, and international graduate course review ${ }^{[7]}$.

\section{Conclusion}

The integration of big data with international postgraduate ideological and political education can effectively enhance the attractiveness of management education on a deeper level, improve the level of international postgraduate research, and deepen the educational effect of campus cultural activities. Although there are some research results on postgraduate work in the field of international governance, there are only several scientific studies but more applied research in the field of university ideological and political education; in addition, there is insufficient practical experience and institutional mechanisms. Driven by problems, big data research will go deeper, and combining practice must be applied to international ideological and political work in the new era.

\section{Funding}

(1) "Comparative Study of the Cultivation of Chinese-English Translation Ability in China Mainland, Hong Kong SAR, and China Taiwan" of Hunan Provincial Philosophy and Social Science Foundation (Project Number: 18JD71).

(2) The Postgraduate Civics Courses Construction Project of Central South University, "Research on the Quality of Curriculum Civics for International Postgraduates."

(3) The Central South University Graduate Course Ideological and Political Construction Project, "Curriculum Ideological and Political Quality Improvement Research for International Graduate Students" (Project Number: 2021JY089).

(4) The Central South University Education Reform Research Project, "Online Learning Evaluation System for Continuing Education” (Project Number: 2021JY204).

\section{Disclosure statement}

The authors declare that there is no conflict of interest.

\section{References}

[1] Tan S, 2021, Analysis and Discussion on the Acceptance Mechanism of Ideological and Political Education of College Students in the Information Technology Era - Comment on "Research on the Acceptance Mechanism of Ideological and Political Education of College Students in the New Media Environment". Yangtze River, 2021(09): 242.

[2] Zhang Y, Liu X, 2016, The Enlightenment of the Big Data Era to the Ideological and Political Education of Graduate Students. Degrees and Graduate Education, 000(003): 39-42.

[3] Wang S, 2017, Challenges and Countermeasures for Postgraduate Ideological and Political Education in the Era of Big Data. Journal of Liaoning Economic Vocational and Technical College, 94(006): 6971.

[4] Zhang M, 2021, Research on the Innovation and Development of Ideological and Political Education in Colleges and Universities in the Big Data Era. Education Teaching Forum, 2021(22): 57-60. 
[5] Yin D, 2015, Analysis of the Reasons for the Weakening of the Effectiveness of Ideological and Political Education in Colleges and Universities and Its Countermeasures. Chinese Journal of Education, 2015(S2): 75-76.

[6] Wang Y, Liu M, 2015, Challenges and Countermeasures of Ideological and Political Education in Colleges and Universities Under the Background of the Internet Age. Chinese Journal of Education, 2015(S2): 356-360.

[7] Cong B, Yun N, Ma B, 2019, Explore the Impact of Big Data on Graduate Ideological and Political Education. Chinese Legend, 2019(5): 122-123.

Publisher's note

Bio-Byword Scientific Publishing remains neutral with regard to jurisdictional claims in published maps and institutional affiliations. 